\title{
ANALISIS PROGRAM MASTURAH JAMA'AH TABLIGH DAN IMPLIKASINYA TERHADAP KELUARGA SAMARA
}

\author{
SURATNO, DODI YUDO SETYAWAN \\ Institut Informatika dan Bisnis Darmajaya \\ Email : suratnoafra@darmajaya.ac.id,dodi@darmajaya.ac.id
}

\begin{abstract}
:
The realization of the sakinah mawadah warahmah (samara) family is the ideal of every family. Some parameters for the realization of such a family are a wife in a household that is 'Alimah, Zahidah,' Abidah, Murabbiyah, Khaddimah and Da'iya. Many methods can be applied to make it happen, in this study focused on the method of khuruj fisabilillah masturah jama'ah tabligh. This method jama'ah husband and wife out of the house in a few days to do da'wah and study religion specifically. By analyzing the method, it was found $79.16 \%$ increase in the number of samara family parameters achieved by the family carrying out the activity.
\end{abstract}

Keywords : sakinah, masturah, tabligh

\section{PENDAHULUAN}

Kata sakinah itu sendiri menurut bahasa berarti tenang atau tenteram. Menikah karena Allah akan mendapatkan kemudahan dari Allah [1] Dengan demikian, keluarga sakinah berarti keluarga yang tenang atau keluarga yang tenteram. Sebuah keluarga bahagia, sejahtera lahir dan batin, hidup cinta- mencintai dan kasih-mengasihi di mana suami bisa membahagiakan istri. Sebaliknya, istri bisa membahagiakan suami dan keduanya mampu mendidik anak-anaknya menjadi anak- anak yang saleh dan salehah, yaitu anak-anak yang berbakti kepada orang tua, kepada agama, masyarakat, dan bangsanya.

Selain itu, keluarga sakinah juga mampu menjalin persaudaraan yang harmonis dengan sanak famili dan hidup rukun dalam bertetangga, bermasyarakat dan bernegara. Faktor terbesar terwujudnya keluarga sakinah adalah seorang istri yang taat kepada suaminya [2]. Perkawinan adalah ikatan lahir batin antara seorang pria dengan seorang wanita sebagai suami isteri dengan tujuan membentuk keluarga, rumah tangga yang bahagia dan kekal berdasarkan Ketuhanan Yang Maha Esa.

Undang-Undang Nomor 1 Tahun 1974 Tentang Pernikahan Pasal 1 mendefinisikan bahwa pernikahan ialah ikatan lahir batin antara seorang pria dengan seorang wanita sebagai suami isteri dengan tujuan membentuk keluarga (rumah tangga) 
yang bahagia dan kekal berdasarkan Ketuhanan Yang Maha Esa [3]. Di dalam Kompilasi Hukum Islam dikatakan bahwa Pernikahan menurut hukum Islam adalah akad yang sangat kuat atau mitsaqan ghalidzan untuk mentaati perintah Allah dan melaksanakannya merupakan ibadah. Pernikahan bertujuan untuk mewujudkan kehidupan rumah tangga yang sakinah, mawaddah, dan rahmah [4]. Istri yang taat adalah istri yang mengetahui kewajibannya dalam agama untuk mematuhi suaminya dan menyadari sepenuh hati betapa pentingnya mematuhi suami. Istri harus selalu menaati suaminya pada hal-hal yang berguna dan bermanfaat, hingga menciptakan rasa aman dan kasih sayang dalam keluarga.

Berdasarkan pendapat di atas, kepatuhan istri kepada suami adalah kepatuhan yang bersifat proporsional, dengan batasan tidak melanggar perintah Allah. Kepatuhan istri tidak diartikan sebagai kepatuhan yang didasarkan kepada kewenangan memerintah, dan menjadikan istri sebagai bawahan suami, tetapi lebih diartikan sebagai kepatuhan yang didasarkan pada kasih sayang, sebagaimana tujuan perkawinan untuk membentuk keluarga yang sakinah, mawaddah warahmah. Tujuan pertama hukum pernikahan Islam adalah untuk melindungi moral manusia [5]. Program Masturah adalah suatu program Jamaah Tabligh yang merupakan kegiatan yang dibuat oleh serombongan minimal tiga pasangan suami istri yang mendidik; berisi menghidupkan amalan-amalan masjid di dalam rumah, sehingga bertujuan menjadikan rumah indah seperti rumah nabi Muhammad saw baiti jannati, rumahku surgaku. Sehingga tujuan dari pernikahan membentuk keluarga sakinah mawaddah dan rahmah dapat tercapai sempurna [6][7].

Menurut M. Quraish Shihab, kata sakinah terambil dari bahasa Arab yang terdiri dari huruf-huruf sin, kaf, dan nunyang mengandung makna ketenangan atau antonim dari kegoncangan dan pergerakan [8]. Berbagai bentuk kata yang terdiri dari ketiga huruf tersebut kesemuanya bermuara pada makna sebagaimana telah diterangkan sebelumnya. Misalnya, rumah dinamai maskan karena ia adalah tempat untuk meraih ketenangansetelah penghuninya bergerak bahkan boleh jadi mengalami kegoncangan di luar rumah.

Yunasril Ali menyatakan keluarga sakinah dalam perspektif al-Qur'an dan hadis adalah: Keluarga yang memiliki mahabbah, mawaddah, rahmah, dan amanah [9]. Pernikahan sebagai perbuatan hukum antara suami dan isteri, bukan saja bermakna untuk 
merealisasikan ibadah kepada-Nya, tetapi sekaligus menimbulkan akibat hukum keperdataan di antara keduanya. Namun demikian karena tujuan perkawinan yang begitu mulia, yaitu membina keluarga bahagia, kekal, abadi berdasarkan ketuhanan Yang Maha Esa maka perlu diatur hak dan kewajiban suami dan istri masing-masing. Apabila hak dan kewajiban masing-masing suami dan isteri terpenuhi, maka dambaan suami isteri dalam bahtera rumah tangganya akan dapat terwujud, didasari rasa cinta dan kasih sayang [10]. Mereka berdua bagaikan satu jiwa di dalam dua tubuh. Masing-masing mereka berusaha untuk membuat kehidupan yang lain menjadi indah dan mencintainya sampai pada taraf ia merasakan bahagia apabila yang lain merasa bahagia, merasa gembira apabila ia berhasil mendatangkan kegembiraan bagi yang lainnya.

Inilah dasar kehidupan suami isteri yang berhasil dan bahagia dan juga dasar dari keluarga yang intim yang juga merupakan suasana di mana putera-puteri dapat dibina dengan budi pekerti yang mulia [11]. Antara suami isteri dalam membina rumah tangganya agar terjalin cinta yang lestari, maka antara keduannya itu perlu menerapkan sistem keseimbangan peranan, maksudnya peranannya sebagai suami dan peranan sebagai isteri di samping juga menjalankan peranan-peranan lain sebagai tugas hidup sehari-hari [12].

\section{Landasan Hukum Keluarga Sakinah}

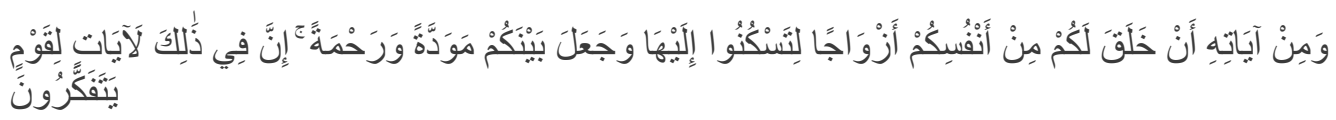

Terjemahan :

Dan di antara tanda-tanda kekuasaan-Nya ialah Dia menciptakan untukmu isteriisteri dari jenismu sendiri, supaya kamu cenderung dan merasa tenteram kepadanya, dan dijadikan-Nya di antaramu rasa kasih dan sayang. Sesungguhnya pada yang demikian itu benar-benar terdapat tanda-tanda bagi kaum yang berfikir. QS.Ar-Rum:21

Kata "litaskunu" diartikan "agar cenderung dan merasa tenteram (sakinah)". Sakinah menurut Quraish Shihab adalah ketenangan yang dinamis dan aktif. Untuk mencapai sakinah diperlukan kesiapan fisik, mental, dan ekonomi, karena ketenangan itu memerlukan pemenuhan kebutuhan fisik dan ruhani [13].

Islam melihat pernikahan sebagai ibadah sosial [14] Memilih pasangan yang tepat merupakan hal yang gampang-gampang susah. Hal ini berkaitan dengan masalah 
takdir dan juga selera masing-masing orang. Pasangan hidup atau jodoh memang merupakan hak prerogatif Allah. Tetapi sebagai hamba-Nya yang baik, kita diwajibkan berusaha mencari dan memilih pasangan sesuai dengan aturan syari'at. Di samping itu, dalam rangka mencari dan memilih pasangan yang tepat, hendaknya memahami alasan yang tepat dalam memilih pasangan, mengetahui tipe-tipenya calon suami atau istri yang baik di samping selalu mohon petunjuk dari Allah dengan melakukan salat istikharah, agar mendapat ridho-Nya

\section{METODE PENELITIAN}

Salah satu maksud masturah di Ponpes Al-Kirom Kebon Bibit Haji Mena Lampung Selatan sebagai objek penelitian adalah untuk membentuk Pemahaman agama pada diri seseorang wanita, karena setiap hari wanita selalu disibukkan dengan urusan rumah tangga sehingga dominasi pemikiran dan hari-harinya hanya urusan dunia. Oleh karena itu dengan keluar ke jalan agama diharapkan setelah pulang ke rumah dapat membawa pemahaman terhadap agama untuk bekal menghadap Allah, sehingga akan menjadikan wanita tersebut asbab hidayah bagi keluarganya. Hal ini diimplementasikan dengan beberapa amalan yang perlu wujud dalam rumah: Menjadi 'Alimah (pengajar): wanita yang berilmu dengan menjaga ta'lim secara istiqamah. Ta'lim adalah perintah Allah dan salah satu sunnah Rasulullah saw, ta'lim adalah roh agama, dan ta'lim adalah salah satu pintu gerbang masuknya agama ke dalam rumah. Zahidah: hidup sederhana.

Hidup sedehana adalah salah satu sunnah cara hidup Rasulullah saw. Dengan hidup sederhana hisab akan mudah dan ringan. Sederhana pakaian, makanan, perumahan, perabotan, penampilan dan sebagainya.'Abidah: Ahli ibadah, menjaga salat di awal waktu, zikir pagi petang, semua pekerjaan rumah selalu diiringi dengan zikir, istiqamah baca al-Qur'an dan berusaha untuk selalu mengkhatamkannya, salat-salat sunat, puasa wajib dan puasa sunat serta gemar bersedekah. Murabbiyah : Sebagai guru yang mendidik anak-anak secara Islam sesuai dengan yang telah dicontohkan oleh Rasulullah saw; karena anak adalah amanah dari Allah. Tarbiyatul adab: jaga ada-adabnya, tarbiyatul jasad: badan, pakaian dan makanan, tarbiyatul wiladah : setelah melahirkan, tarbiyatul Diin: Agama, kenalkan agama sejak anak-anak masih kecil, latih untuk selalu takut hanya kepada Allah, tanamkan pada anak cinta Allah dan Rasul-Nya, cinta saudara dan sebagainya. Khaddimah : Selalu berkhidmat untuk suami dan anak - anak dalam setiap 
menunaikan keperluan dan kebutuhan suami dan anak-anak serta setiap tamu yang datang ke rumah dengan ikhlas karena Allah. Da'iyah : Mengajak manusia untuk selalu ta'at kepada Allah dan kepada Rasulullah saw dengan menanamkan iman yakin kepada kampong akhirat, dan sebagainya.

Dengan metode wawancara yang dilakukan kepada jama'ah tabligh yang akan dan sesudah melaksanakan masturah. Wawancara dilakukan untuk memperolah data dari dua belas jama'ah masturah apakah keluaga yang akan melalukan tersebut terutama istria sudah berkriteria 'Alim, Zahidah, 'Abidah, Murabbiyah, Khaddimah dan Da'iyah. Selain itu juga dilakukan analisis terhadap metode masturah jamaah tablig tersebut.

\section{PEMBAHASAN}

Maqomi Masturah adalah: ta'lim rumah dan ta'lim muhallah. Terdapat mudzakarah mudzakarah di dalam program ini sebagai berikut:
a) 6 sifat sahabat
b) 20 usul - usul dakwah
c) Maqomi rijal
d) Maqomi masturah
e) Mendidik anak secara Islam
f) Dakwah iman yakin
g) Adab safar (perjalanan)
h) Adab rumah tangga
i) Adab mandi dan tandas

Arti pentingnya masturah keluar di jalan Allah adalah Pemimpin keluarga adalah suami tetapi pemimpin rumah tangga adalah istri, Ibu adalah madrasahnya anak-anak, Ibu adalah universitas terbesar bagi anak-anaknya, sikap dan cara berfikir ibu sangat besar pengaruhnya bagi anak dan penghuni rumahnya, keluarganya dan lingkungan tetangganya. Karena itu sangat penting bagi wanita untuk mempunyai pengetahuan dan fikir agama, Apabila di rumah, ibu selalu disibukkan dengan urusan rumah tangga seperti mengurus anak, membersihkan rumah, memasak dan sebagainya sehingga sulit untuk belajar agama dengan benar. 
Apabila kita keluar di jalan Allah, maka kita akan berada dalam suasana yang berbeda, terlepas dari urusan dunia, sehingga kita dapat belajar agama dengan benar, dan Insyaallah fikir agama bisa masuk dalam hati. Dan apabila pulang ke rumah, kita tahu bahwa kita punya tanggung jawab untuk menanamkan fikir agama kepada anak-anak kita, pembantu- pembantu kita, keluarga kita, orang-orang di sekitar kita dan siapapun yang bertemu dengan kita.

Di akhirat kelak kita akan ditanya tentang: salat kita, puasa kita, zakat kita dan amal perbuatan lainnya. Sebagai muslim, baik laki-laki maupun wanita mempunyai tanggung jawab dakwah, maka wanita pun akan diminta pertanggungjawabannya mengenai dakwah. Dari rumah yang ibunya mempunyai fikir agama, maka akan lahir anak- anak yang saleh dan salehah. Dari kisah-kisah para nabi, dapat dilihat dari istri nabi yang tidak punya fikir agama seperti nabi Nuh as. Beliau berdakwah selama 950 tahun hanya mendapat pengikut 83 orang. Anaknya menjadi kafir, kaumnya dimusnahkan oleh Allah. Nabi Luth as., istrinya menentang dakwah, anaknya menjadi kafir. Kaumnya juga dimusnahkan oleh Allah.

Sebaliknya nabi Ibrahim as., istri-istrinya adalah wanita yang punya fikir agama, sehingga beliau mendapat banyak pengikut dan dari keturunannya lahir nabi Ishaq as., nabi Yusuf as., nabi Daud as., nabi Sulaiman as., nabi Isa as., dan dari Siti Hajar lahir nabi Ismail as., yang dari keturunannya lahir nabi Muhammad saw. Demikian pula istri-istri Rasulullah saw mampunyai fikir agama, terutama Khadijah r.ha yang telah mengorbankan seluruh harta bendanya untuk penyebaran agama Allah, dan beliaulah yang selalu menghibur, mendorong suaminya untuk syi'arnya Islam, sehingga kurang lebih 23 tahun Nabi berdakwah, seluruh jazirah Arab masuk Islam. Setelah nabi wafat perjuangan dakwah dilanjutkan oleh para sahabatnya dengan pengertian dan dorongan para istrinya sehingga tidak beberapa lama $2 / 3$ belahan bumi menjadi Islam.

Demikianlah semua ini berkat pengaruh dan fikir kaum wanita, Seorang wanita salehah lebih baik dari 70 aulia, sedangkan wanita yang akhlaknya buruk lebih jahat dari 1000 laki-laki yang jahat dan dia akan menyeret 4 laki-laki ke neraka jahannam yaitu: suami, bapak, Saudara laki-laki, dan anak laki-lakinya, Di zaman ini kerja dakwahpun dimulai dari seorang wanita yang punya fikir agama yaitu nenek Maulan Ilyas rah.a. Beliau ingin mempunyai keturunan yang mempunyai fikir agama, maka dinikahkanlah 
putrinya dengan seorang ulama dan darinya lahirlah Maulana Ilyas rah.a. Jadi sangat perlu sekali wanita ikut ambil bagian dalam usaha dakwah ini. Agama akan sangat lambat sekali perkembangannya apabila para wanitanya tidak ikut usaha dakwah. Ibarat pedati yang mempunyai roda sebelah, maka jalannya pun akan lama atau seperti seekor burung yang sayapnya patah sebelah.

Jadi pentingnya wanita ikut usaha dakwah karena :

a) Dakwah Rasulpun langsung kepada istrinya

b) Agama Islam tersebar di zaman khulafurrasyidin, 2 orang khalifah masuk Islam dengan asbab wanita, yaitu : Umar r.a asbabnya adalah adiknya Fathimah binti Khattab r.ha dan Usman r.a asbabnya adalah bibinya Saudah r.ha.

c) Jumlah wanita lebih banyak daripada laki-laki, jumlah anak-anak lebih banyak dari wanita, dengan asbab ambil usaha dakwah maka rahmat Islam akan tersebar keseluruh alam.

d) Orang - orang kebatilanan memanfaatkan wanita untuk promosi dunia.

e) Apabila wanita paham agama akan rela berkorban habis-habisan. Seperti Siti Khadijah r.ha dan Sumayyah r.ha.

f) Satu do'a seorang wanita salehah lebih baik daripada doa 70 wali. Tetapi satu wanita jahat lebih rusak daripada 1000 laki-laki jahat

Tertib umum Masturah dan persiapan Masturah keluar di jalan Allah sebagai berikut:

a) Menggunakan garis taqwa ( memakai full hijab/ purdah )

b) Tidak ada amir untuk Masturah, amir hanya dari kaum laki-laki

c) Tanggung jawab masturah adalah tanggung jawab semua jumidar (oleh karena itu jumidar harus tahu kerja Masturah)

d) Kerja Masturah harus terkontrol dan terkendali

e) Semua kerja Masturah hanya boleh berjalan dengan hasil musyawarah laki-laki.

Persiapan Masturah Keluar Di Jalan Allah : 

a) Tafakut
b) Masturah yang hamil $4-8$ bulan boleh keluar Masturah
c) Anak wanita full hijab, anak wanita dengan ibunya, anak laki-laki dengan bapaknya
d) Anak adalah amanah, tapi agama adalah amanah yang paling besar
e) Keluar tanpa membawa anak lebih mujahadah.

Rute-rute Masturah:
a) Lihat kondisi jama'ah, jika jama'ah baru harus keluar di tempat yang sudah 40 hari masturah
b) Amir sudah pernah 4 bulan keular di jalan Alloh, Masturah sudah beberapa kali 3 hari
c) Bila jama'ah sudah berpengalaman, maka kirim ke daerah baru
d) Tempat baru harus ditinjau jangan hanya lewat telepon
e) Kalau ada takazah ke tempat baru harus ada orang lama.

Harus ada pengecekan:

1) Istrinya siap atau tidak, sudah ikut ta' lim atau belum, keinginan istri atau tidak.

2) Rumah selama ditempati Masturah betul-betul diinfakkan

3) Jalur rumah dua pintu (depan dan belakang)

4) Kondisi rumah ada ruangan khusus ta'lim, mulakot dan bayan

5) Dapur terpisah agak jauh / terhijab oleh dinding sehingga ketika masak tidak terganggu

6) Kamar mandi I dan II terpisah

7) Tempat wudhu harus di luar, sebaiknya disediakan banyak seperti di masjid

8) Tempat jemuran pakaian tidak terlihat oleh laki-laki

9) Sandal disimpan supaya tidak terlihat oleh laki-laki.

Adab - adab rumah yang ditempati masturah 
a) Tidak ada terpajang gambar-gambar makhluk hidup, seperti anjing dan patungpatung, karena malaikat rahmat tidak akan memasuki rumah yang ada unsur tersebut.

b) Full hijab, dari luar tidak bisa melihar ke dalam, dari dalam tidak bisa melihat keluar, termasuk pintu juga pakai hijab/ tabir.

c) Pajangan ditutup atau disembunyikan

d) Ada tempat I dan II yang tertutup

e) Ada tempat bayan

f) Semua anggota keluarga yang laki-laki tidak boleh masuk ke dalam rumah selama rumahnya ditempati Masturah

g) Tuan rumah sudah pernah keluar, minimal 3 hari (supaya di rumah tersebut hidup suasana agama, sehingga layak ditempati masturah).

h) Harus dibentuk hirosah (security) kalau jarak rumah dengan masjid agak jauh (1 orang anshar dan 1 orang muhajirin)

i) Ketika rombongan datang ke lokasi, maka 2 orang rijal memeriksa ke dalam rumah, kalau belum siap perlu dibetulkan dulu, Masturah menunggu di dalam mobil.

j) Hidayah akan turun dengan hijrah dan nusrah, nusrah yang paling tinggi nilainya, menyediakan rumah untuk ditempati masturah

k) Yang mengetuk pintu atau bayan siap dimulai ialah petugas istiqbal dengan mengetuk 3 kali.

\section{Tahapan Pelaksanaan Program Masturah.}

Sesungguhnya agama akan hidup hanya dengan dakwah, dan dakwah akan terus berjalan dengan mengwujudkan kerja dakwah, kerja dakwah akan wujud dengan digerakannya jamaah-jamaah baik harian, mingguan, bulan ataupun tahunan. Baik lakilaki dan wanita mempunyai kewajiban yang sama dalam agama oleh karenanya dibentuk dan diberangkatkan jamaah- jamaah masturah. Karena perkara dakwah ini merupakan perkara yang besar sudah seharusnya, banyak hal yang harus jamaah persiapkan ketika memutuskan untuk keluar Masturah sehingga keluarnya jamaah dapat membawa manfaat yang besar, karena jika jamaah keluar tanpa membawa persiapan yang matang 
tidak akan membawa perbaikan kepada diri jamaah dan tidak dapat menarik hidayah Allah. Di Ponpes Al-Kirom Kebon Bibit Hajimena Lampung Selatan ketika masturah akan dilakukan maka ada Hal-hal yang harus jamaah persiapkan di antaranya:

a) Bagaimana istri jamaah bisa mudzakarah pada saat keluar untuk Masturah. Saat keluar adalah saat di mana istri mempraktekkan semua materi mudzakarah yang suami mereka ajarkan di rumah, bukan malah keluarnya istri untuk belajar jamaah mudzakarah, jadi tidak ada alasan ketika keluar istri jamaah tidak mengerti materi mudzakarah, karena seharusnya mudzakarah dilakukan setiap hari sebelum jamaah keluar saat masturah. Kalau sampai pada saat keluar istri jamaah tidak bisa membawakan materi mudzakarah maka yang patut disalahkan adalah suami-suami mereka. Karena seharusnya sebelum jamaah memutuskan keluar Masturah maka hari-hari di rumah kita buat mudzakarah sebanyak 14 materi mudzakarah (Safar, makan, tidur, pesanan wanita, mendidik,anak secara Islami, bagaimana istiqbal, fikir alam, 6 sifat, dan sebagainya). Pada saat mudzakarah di rumah jamaah harus mendengar sendiri secara langsung bagaimana istri jamaah membuat mudzakarah, kalau suami tidak bisa memberikan materi mudzakarah maka sudah seharusnya suami bertanya kepada orang yang bisa setelah itu buat mudzakarah dengan istri di rumah. Jamaah keluar Masturah mau belajar dakwah yang betul, bukan mau belajar mudzakarah, jika jamaah mempraktekan ini maka akan ada kesan yang berbeda dibanding kita berangkat keluar Masturah tanpa persiapan terlebih dulu.

b) Selesaikan semua yang berhubungan dengan pekerjaan (cuti, dan sebagainya) dan masalah anak (titip anak). Selesaikan semua hal yang berhubungan dengan pekerjaan dan anak jauh-jauh hari sebelum keluar Masturah, jangan pas mendekati keluar baru sibuk ijin cuti dan titip anak, sehingga jamaah benar-benar bisa berkonsentrasi untuk keluar (khuruj fisabilillah).

c) Keluar (khuruj si sabilillah) dengan hijab sempurna (bukan cadar tapi purdah, kaos kaki, sarung tangan warna gelap). Hijab sempurna hukumnya wajib ketika keluar Masturah. Selama tidak mau mengenakan hijab sempurna maka tidak dibenarkan untuk keluar (khuruj si sabilillah). 
d) Keluar (khuruj si sabilillah) jangan membawa bermacam-macam buku diktat, Markaz Jakarta tidak pernah mengeluarkan diktat-diktat, buku yang harus dibawa hanyalah Fadilah Amal, fadilah Sedekah, al-Qur'an, dan Muntakhab Ahadis. Di luar dari itu tidak diperkenankan dibawa saat keluar Masturah apalagi dibaca saat mudzakarah.

e) Gunakan tertib yang berlaku di Indonesia, bukan yang berlaku di Pakistan, Bangladesh, India, dan sebagainya. Kerja dakwah bukan apa yang kita lihat, bukan apa yang kita dengar melainkan apa yang sudah di putuskan markaz Jakarta karena setiap negara mempunyai tertib masing- masing tergantung kondisi negara tersebut

f) Bawa alat khidmat sendiri, Jangan mengharap kepada orang tempatan karena itu sama saja mengharap kepada makhluk dan kalau hal itu sampai kita lakukan berarti kita telah menyalahi salah satu dari tertib dakwah, sebagai contoh kita bisa lihat kalau jamaah Pakistan datang ke Indonesia maka mereka membawa alat khitmad sendiri, tidak pernah mengharap alat khitmad dari Indonesia, seharusnya kita juga begitu apalagi kita hanya keluar antar daerah/ halaqoh.

Hal-hal lain yang perlu jamaah sampaikan dan tekankan kepada istri sebelum berangkat keluar Masturah :

a) Waktu keluar jangan membawa barang dagangan, karena waktu keluar ingin menekan dunia bukan malah memasukkan atau menambah dunia, sangat tidak dibenarkan terjadi transaksi jual beli saat keluar.

b) Jangan tanya ke Masturah yang lain tentang pekerjaan suami mereka, gajinya, dan jangan tanya sudah punya anak berapa karena kalau ada Masturah yang mandul akan merasa tersinggung. Jamaah keluar bukan untuk membicarakan hal-hal tersebut, mereka keluar hanya untuk membicarakan perkara agama.

c) Kalau mendengar berita yang tak baik maka sampaikan kepada istri agar membohongkan itu berita, karena jamaah keluar sedang melatih untuk mendengar dan membicaraan hal-hal yang baik-baik saja. Katakan pada istri, "Ketika keluar kamu hanya punya hak untuk melihat kebaikan orang dan kamu 
tidak punya hak melihat keburukan orang." kalau hal ini dilakukan maka akan tumbuh kasih sayang

d) Ketika keluar maka kita targib istri jangan bawa pakaian banyak-banyak, baik ketika keluar 3 hari, 10/15 hari, 40 hari, dan seterusnya.

e) Jangan membawa perhiasan berharga, semua dilepas, karena ketika kita keluar ingin menampilkan penampilan yang semua orang bisa ikut dalam dakwah bukan menampilkan tampilan yang mewah, karena semua orang bisa hidup sederhana tapi tak bisa hidup mewah.

f) Untuk jamaah 3 hari dianjurkan untuk hari pertama membawa makanan sendiri sampai makan malam, sehingga tuan rumah tidak susah dengan kita.

\section{Kehidupan Rumah Tangga Alumni Masturah}

Peneliti mewawancarai dua belas orang informan. Mereka semua berjenis kelamin laki-laki. Sulit kiranya bagi peneliti untuk mewawancarai informan anggota Jamaah Tabligh yang perempuan karena mereka terpisah dan tidak boleh berbaur dengan jamaah laki-laki.

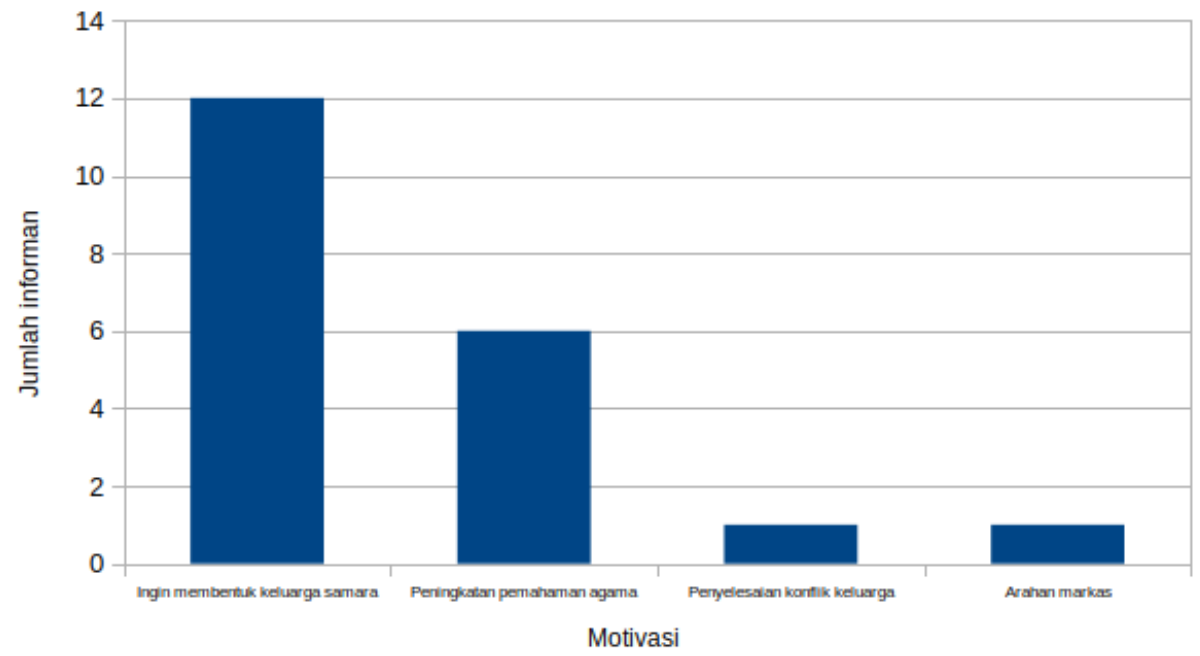

Untuk mengetahui dampak dari program Masturah bagi ketaatan istri dilihat dari parameter 'Alim, Zahidah, 'Abidah, Murabbiyah, Khaddimah dan Da'iyah dapat dilihat pada grafik sebagai berikut. 


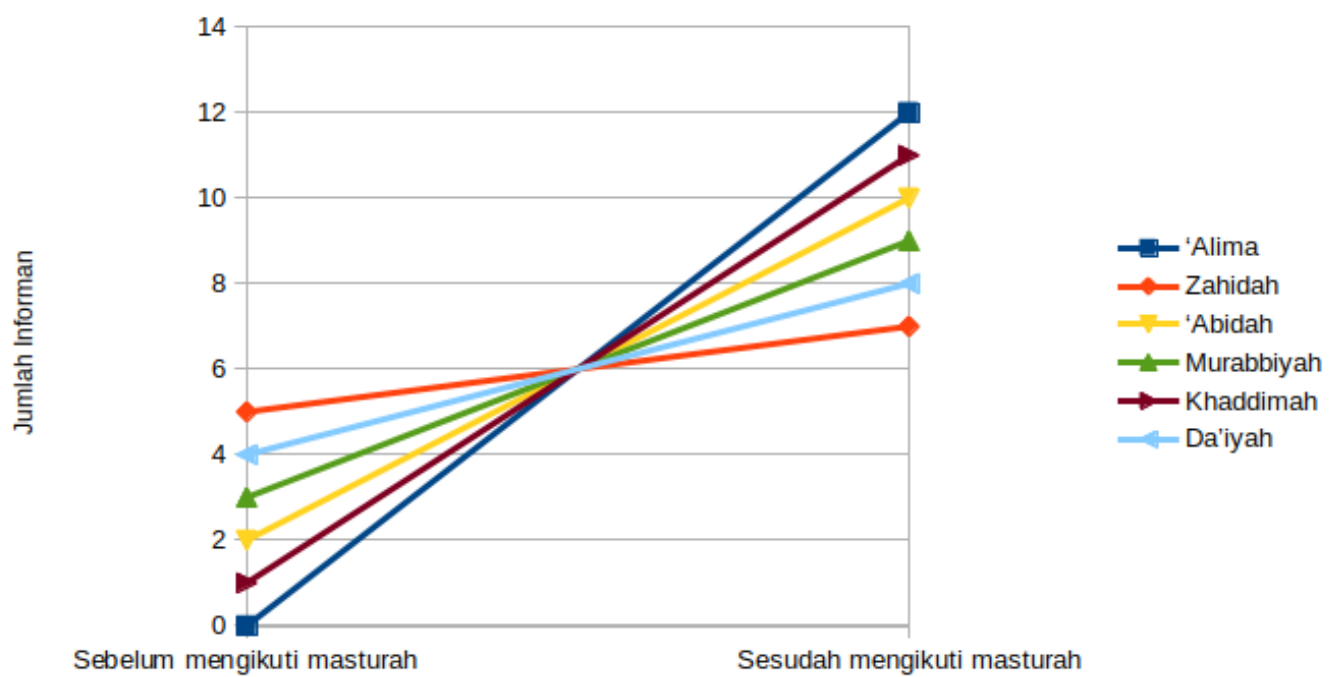

Dari dua puluh masturah mengalami peningkatan jumlah kriteria ketaatan sebesar 79,16\%. Dari jumlah peningkatan tersebut program Masturah ini membuat rumah tangga para anggota Jamaah Tabligh menjadi harmonis dan lebih sakinah.

\section{SIMPULAN}

Program Masturah di kalangan Jamaah Tabligh merupakan program pembinaan keagamaan yang terstruktur dalam membina keluarga sakinah mawaddah warahmah menjadi istri dalam rumah tangga yang lebih taat kepada suaminya dengan ciri- cirinya tampak yaitu 'Alimah, Zahidah, 'Abidah, Murabbiyah, Khaddimah dan Da'iyah sebesar $79,16 \%$ dari jumlah responden penelitan.

\section{DAFTAR PUSTAKA}

[1] Noermanzah, Noermanzah Noe. "Plot in a Collection of Short Stories "Sakinah Bersamamu" Works of Asma Nadia with Feminimism Analysis."HUMANUS: JURNAL ILMIAH ILMU-ILMU HUMANIORA16.1 (2017): 27-40.

[2] Ulya, Anis Rohmatun.Hak dan kewajiban suami terhadap istri dalam AlQuran perspektif M. Quraish Shihab dan M. Ali Ash Shobuni. Diss. UIN Sunan Ampel Surabaya, 2015.

[3] Sembiring, Rosnidar, and Rabiatul Syahriah. "Analisis Hukum Perceraian Karena Gugatan Istri dengan Alasan Perselisihan dan Pertengkaran Sehingga Tidak Dapat Hidup dalam Berumah Tangga Dikaitkan dengan Undang-Undang Nomor 1 Tahun 1974 Tentang Perkawinan (Studi Putusan Nomor: 128/Pdt. g/2015/PA. Ppg.)." (2019). 
[4] Arifin, Irfan Samsul. Keluarga sakinah dalam kompilasi hukum islam pasal 3 perspektif lembaga kemaslahatan keluarga nahdlatul ulama (LKKNU) Jawa Barat. Diss. UIN Sunan Gunung Djati Bandung, 2018.

[5] Shofiyani, Anisa Fitri, et al. Motivasi Ibu Rumah Tangga Belajar Bahasa Arab dan Pengaruhnya Dalam Mempelajari Al-Quran (Studi Kasus Ibu Rumah Tangga Mustawa Tsalits Mahad Abu Bakar Ash-Shiddiq Universitas Muhammadiyah Surakarta Tahun Pelajaran 2015-2016). Diss. Pascasarjana Magister Pendidikan Islam, 2016.

[6] Umar, Hamdan.KOMUNITAS JAMAAH TABLIGH DI KALANGAN MAHASISWA SURABAYA (1990-2015 M). Diss. UIN Sunan Ampel Surabaya, 2016.

[7] Thalib, Thalib. "POLA PEMBINAAN JAMAAH MASTURAT DALAM MEMBANGUN RUMAH TANGGA SAKINAH PADA MASYARAKAT ISLAM SUKU TERASING DI DESABOBALO KEC. PALASA KAB. PARIGI MOUTONG."Istiqra: Jurnal Hasil Penelitian 4.2 (2016): 341364.

[8] Muhammad, Munazir. Bagian Anak Laki-Laki Dan Anak Perempuan Dalam Warisan Studi Komperatif Pemikiran Munawir Sjadzali dan M. Quraish Shihab (Studi Kasus Di Kecamatan Lubuk Pakam). Diss. Universitas Islam Negeri Sumatera Utara Meddan, 2018.

[9] Muhajarah, K. U. R. N. I. A. "Krisis Manusia Modern dan Pendidikan Islam." Al Ta'dib 7.2 (2018): 188-204

[10] Shomad, Abd. Hukum Islam: Penormaan Prinsip Syariah dalam Hukum Indonesia. Kencana, 2017.

[11] Asmani, Jamal Mamur. "Rekonstruksi Teologi Radikalisme di Indonesia, Menuju Islam Rahmatan Lil Alamin." Wahana Akademika: Jurnal Studi Islam dan Sosial 4.1 (2017): 3-18.

[12] Setyonaluri, Diahhadi. "Memasuki mahligai pernikahan: Pola perkawinan di Indonesia."Memetik Bonus Demografi. Rajawali Pers, 2018. 257-272.

[13] Prasetiawati, Eka. "Penafsiran Ayat-Ayat Keluarga Sakinah, Mawaddah, Wa Rahmah dalam Tafsir al-Misbah dan Ibnu Katsir." Nizham Journal of Islamic Studies 5.2 (2017): 138-166.

[14] Shofiyani, Anisa Fitri, et al. Motivasi Ibu Rumah Tangga Belajar Bahasa Arab dan Pengaruhnya Dalam Mempelajari Al-Quran (Studi Kasus Ibu Rumah Tangga Mustawa Tsalits Mahad Abu Bakar Ash-Shiddiq Universitas Muhammadiyah Surakarta Tahun Pelajaran 2015-2016). Diss. Pascasarjana Magister Pendidikan Islam, 2016. 